\title{
Total kalça protezinde çimentolu ve çimentosuz tespit yöntemlerinin başarısı arasında fark var mıdır?
}

\author{
Is there a difference between the success of cemented and cementless \\ fixation methods in total hip replacement?
}

\author{
Emre Anıl Özbek ${ }^{1}$, Bülent Erdemli²
}

\begin{abstract}
'Sağlık Bakanlığı Yozgat Şehir Hastanesi Ortopedi ve Travmatoloji Kliniği, Yozgat
${ }^{2}$ Ankara Üniversitesi Tıp Fakültesi, Ortopedi ve Travmatoloji Anabilim Dalı, Ankara
\end{abstract}

Total kalça artroplasti cerrahisi en başarılı cerrahi girişimlerden biri olmak ile birlikte, primer total kalça artroplasti cerrahisi sırasında kullanılan çimentolu ve çimentosuz tespit yöntemlerinin başarısı arasındaki tartışma devam etmektedir. Literatürde, bu iki yöntemin başarısını; ameliyat sonrası ağrı, ameliyat sonrası revizyon oranları, mortalite, implant sağkalımı ve fonksiyonel sonuç açılarından karşılaştıran birçok randomize kontrollü meta-analiz ve sistematik derleme yayımlanmıştır. Bunlara ek olarak, çimentolu ve çimentosuz yöntemlerin farklı yaş gruplarına uygulanmaları ile ameliyat sonrası başarı oranı arasında korelasyon olduğunu bildiren tartışmalı görüşler de mevcuttur. Bu yayınların sonuçlarına bakılırsa, iki yöntem arasında istatistiksel olarak anlamlı bazı farklılıklar saptanmasına rağmen bunların günlük klinik pratik uygulama içerisinde ne kadar etkili olduğu tartışmalıdır. Bu derlemenin amacı ise, literatürde çimentolu ve çimentosuz yöntemlerin ameliyat sonrası erken ve uzun dönem başarılarını değerlendiren yayınların, sistematik derlemelerin, meta-analizlerin derlenmesi ve buna ek olarak, kıdemli artroplasti cerrahı olan yazarların bu iki yöntemin ameliyat sonrası başarı oranları hakkında, günlük klinik pratik uygulama açısından görüşlerinin bildirilmesidir.

Anahtar sözcülkler: total kalça protezi; çimentolu total kalça protezi; çimentosuz total kalça protezi; fonksiyonel sonuç
Total hip arthroplasty surgery is one of the most successful surgical procedure, but the confluence between the success of cemented and uncemented fixation methods used during primary total hip arthroplasty surgery still continues. There exist quite an amount of randomized controlled meta-analysis and systematic reviews which compare the success rates of these two fixation methods with respect to postoperative pain, postoperative revision rates, mortality, implant survival, and functional outcome. In addition, there are controversial arguments that there is a correlation between the application of cemented and uncemented methods to different age groups and their postoperative success rates. Although there are some statistically significant differences between these two methods in the results of these publications, how effective these are in daily clinical practice is debatable. The purpose of this review is to report the results of these publications; summing up the systematic reviews, meta-analyses, and comments of the authors who are senior arthroplasty surgeons in daily clinical practice on the postoperative success rates of these two fixation methods.

Key words: total hip arthroplasty; cemented total hip arthroplasty; cementless total hip arthroplasty; functional outcome
T otal kalça artroplastisi (TKA), ameliyat sonrası fonksiyonel kazanç sağlayıcı ve ağrı giderici bir yöntem olması yanı sıra en başarılı ve uygun maliyetli cerrahi yöntemler arasındadır.. ${ }^{[1]}$ TKA sırasında komponent tespiti olarak kullanılan başlıca üç yöntem vardır ${ }^{[2]}$; total çimentosuz tespit (Şekil 1), total çimentolu tespit ve hibrid tespit (çimentosuz asetabular komponent tespitine ek olarak çimentolu femoral tespit) (Şekil 2 ve 3). Bu derleme içerisinde hibrid yöntem çimentolu yöntem olarak anılacaktır. Çimentolu (TKAÇ) ve çimentosuz (TKAÇs) tespit yöntemlerinin birbirine üstün olduğu durumlar mevcuttur. TKAÇ yönteminde kullanılan kemik çimentosu endüstri tarafından her geçen gün geliştiriliyor olsa da, patofizyolojisi hala kesin olarak açıklanamayan bir şekilde, çimento ve polietilen parçaları pernisiyöz granülomatöz

- İletişim adresi: Dr. Emre Anıl Özbek, Erdoğan Akdağ mah. Viyana caddesi Yozgat Şehir Hastanesi 66100, Yozgat, Türkiye Tel: 0354 - 2190010 e-posta: anl_ozbek@hotmail.com

- Geliș tarihi: 24 Ocak 2019 Kabul tarihi: 24 Ocak 2019 


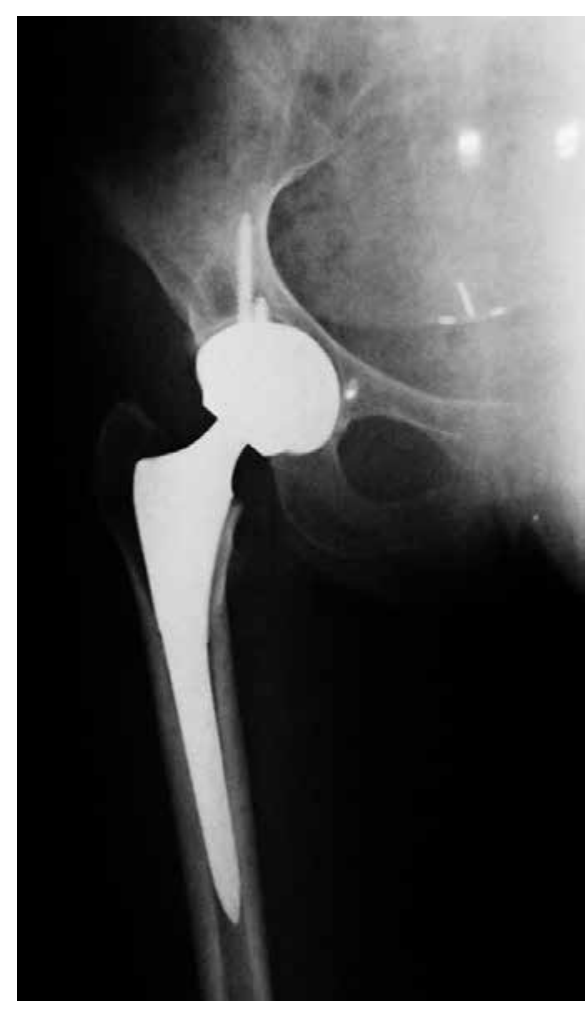

Şekil 1. Opere sağ çimentosuz TKA.

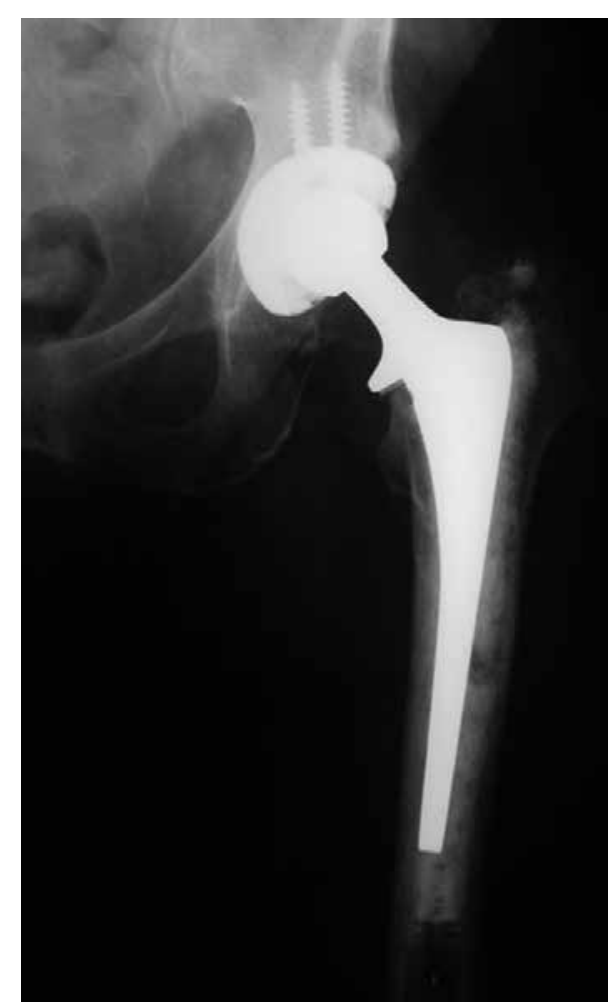

Şekil 2. Opere sol hibrid tespit yöntemi ile gerçekleştirilmiş TKA.
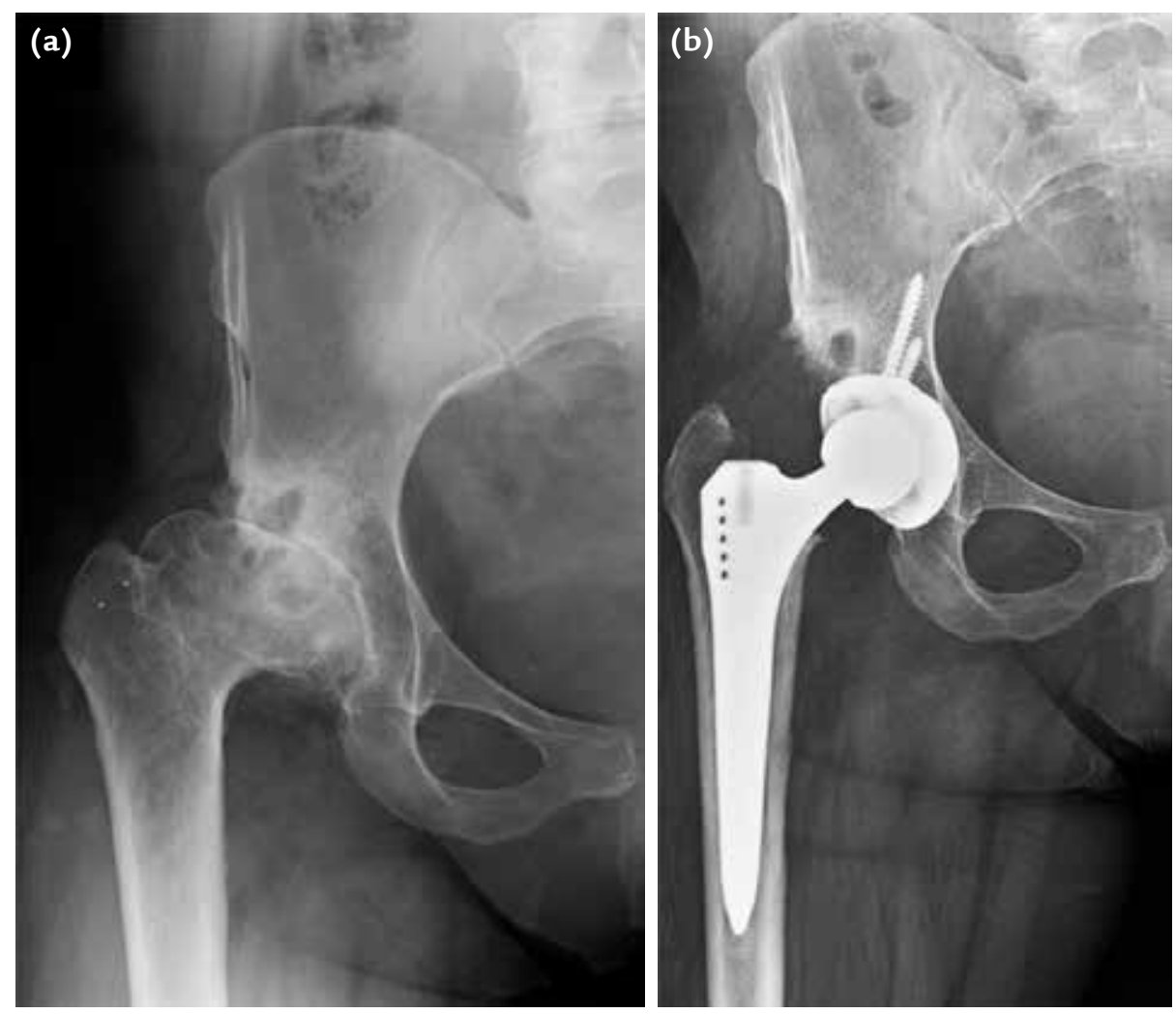

Şekil 3. a, b. Sağ koksartroz, Dorr Tip 3 femur (a). Çimentosuz kare kesit femoral stem ile gerçekleştirilmiş TKA (b). 
reaksiyona yol açarak kemik erozyonuna neden olmaktadır. ${ }^{[3]}$ Biyolojik tespit yöntemi olan TKAÇs, implant sağkalımı ile ilgili yapılan çalışmalarda beklenildiği üzere üstün olarak raporlanmıştır; TKAÇ yönteminde görülen tespit kaybı, ameliyat sonrası zaman ile doğru orantılıdır. ${ }^{[4,5]}$ Literatürde, bu iki yöntemin tromboemboli üzerine etkisini karşılaştıran çok fazla yayın olmamak ile birlikte, TKAÇs'nin tromboemboli açısından daha güvenli bir yöntem olduğu düşünülmektedir. ${ }^{[6]}$ Bununla birlikte, Amerika Birleşik Devletleri merkezli implant maliyetini değerlendiren çalışmalarda, TKAÇs TKAÇ'ye göre daha yüksek maliyetli bir cerrahi girişim olarak bildirilmiştir. ${ }^{[7]}$

Bu derlemede, çimentolu ve çimentosuz tespit yöntemlerinin ameliyat sonrası ağrı komplikasyonları ve implant sağkalımları üzerine etkisi, yaş grubuna göre tercih edilen tespit yöntemi farklılıkları; alt başlıklarda, literatüre ait sonuçlar ışığında tartışıımış ve yazarların konu ile klinik pratik uygulamaları bildirilmiştir.

\section{Ameliyat Sonrası Fonksiyonel Sonuç}

TKA cerrahisi ardından ameliyat sonrası fonksiyonel sonuç değerlendirilmesinde en sık kullanılan yöntemlerden biri Harris Kalça Skorlaması (HHS) yöntemidir. ${ }^{[1]}$ Literatürde, ameliyat sonrası erken dönemde TKAÇ yönteminin fonksiyonel sonuçlarının erken yük vermeye izin vermesi nedeniyle daha iyi olduğunu bildiren çalışmalar görülmektedir. Bununla birlikte, TKAÇ ve TKAÇs yöntemlerinin ameliyat sonrası uzun dönem (>5 yıl) HHS sonuçlarını karşılaştıran yayınlarda ${ }^{[8-12]}$ ve konu ile ilgili yapılan meta-analiz sonuçlarında, iki yöntem arasında fonksiyonel sonuçlar açısından anlamlı farklılık olmadığı kanısına varılmaktadır. ${ }^{[1,2,13]}$

\section{Ameliyat Sonrası Kısa ve Uzun Dönem Ağrı Sonuçları}

Ameliyat sonrası erken dönemde TKAÇ daha iyi bir kemik-çimento-protez entegrasyonu sağladığı için, çok erken yük vermeye izin veren ve dramatik olarak ağrı hafiflemesini sağlayan bir tespit yöntemidir. ${ }^{[1]}$ Literatürde TKAÇ ve TKAÇs tespit yöntemlerini ameliyat sonrası erken dönem ağrı sonuçları açısından karşılaştıran birçok çalışma ve meta-analiz vardır. ${ }^{[1,14-17]}$ Çalışmalar sonucunda, ameliyat sonrası erken dönem ağıı sonuçları TKAÇ yönteminde daha iyi olarak saptanırken, uzun dönem ağrı sonuçlarına etkisi arasında istatistiksel açıdan anlamlı farklar saptanmamıştır. ${ }^{[14-17]}$ Bununla birlikte, Abdulkarim ve ark. tarafından, altı geniş kapsamlı çalışmanın dahil edildiği 695 hastayı kapsayan meta-analiz çalışmasında; TKAÇ yönteminin erken dönem ve uzun dönem ağrı sonuçları üzerine TKAÇs yöntemine göre üstün olmadığı sonucuna varılmıştır. ${ }^{[1]}$

\section{Ameliyat Sonrası Komplikasyonlar ve Mortalite Oranları}

TKA hasta memnuniyetinin en yüksek olduğu cerrahi prosedürlerden olmakla birlikte, ameliyat sonrası tromboemboli, periprostetik enfeksiyon, kalça çıkığı, osteoliz ve mortalite gibi komplikasyonlar gelişebilmektedir. TKAÇ ve TKAÇs sonrasında ameliyat sonrası komplikasyonlar ve mortalite oranlarını karşılaştıran birçok meta-analizde, her iki yöntem arasında mortalite ve ameliyat sonrası komplikasyon riskleri arasında anlamlı farklılıklar saptanmamıştır. ${ }^{[1,3]}$

\section{İmplant Sağkalımı}

TKAÇ yönteminde implant sağkalımı ile ameliyat sonrası zaman arasında negatif bir korelasyon olduğu birçok çalışma ile ortaya konmuştur. ${ }^{[2,3]}$ Bununla birlikte, septik ve aseptik protez yetmezliği gibi alt başlıklar altında iki yöntem karşılaştırıldığında, sonuçlar farklılık göstermektedir. ${ }^{[2]}$ Phedy ve ark. tarafindan yapılmış, konu ile ilgili 30'a yakın randomize kontrollü çalışma ve kohort çalışmalarının dahil edildiği meta-analiz, literatürdeki konu ile ilgili en geniş kapsamlı yayın olarak tespit edilmiştir. ${ }^{[2]}$ Bu çalışmanın sonucunda, TKAÇ ve TKAÇs sonrasında septik veya aseptik nedenlerden herhangi biri nedeniyle ve sadece aseptik nedenlerden ötürü revizyon cerrahisi geçiren hasta sayıları arasında istatiksel anlamlı fark saptanmamıştır. Bununla birlikte, sadece septik nedenlerden ötürü revizyon cerrahisi geçiren hasta sayıları göz önüne alındığında, TKAÇ yönteminin daha üstün olduğu sonucuna varılmıştır. ${ }^{[2]}$ Aynı çalışma içerisinde, iki yöntemin ameliyat sonrası kalça çıkığı üzerine etkileri karşılaştırılmış ve iki yöntem arasında istatistiksel açıdan anlamlı fark saptanmamıştır. Konu ile ilgili yapılan, 700'e yakın hastanın dahil edildiği bir başka meta-analiz çalışmasında ise, TKAÇ ve TKAÇs sonrasında ameliyat sonraSı septik veya aseptik protez yetmezliği nedenleri göz önüne alınmadan revizyon cerrahisi geçiren hasta sayıları karşılaştırılmış ve iki yöntem arasında fark saptanmamıştır. ${ }^{[1]}$

\section{Yaş Grubuna Göre Tespit Yöntemi Tercihi}

TKAÇ tespit yöntemini tüm yaş gruplarında aynı şekilde uygulayan cerrahi ekoller bulunmakta ise de, sadece 75 yaş üstü yaşlı hasta grubunda tercih eden görüşler de bulunmaktadır. ${ }^{[13]}$ Bunun temel nedeni, TKAÇ yöntemindeki tespit kaybının ameliyat sonrası zaman ile olan ilişkisidir. Literatürde farklı yaş grupları (45-64, 65-74, 75 yaş üstü) için iki tespit yöntemi başarısını revizyon cerrahi gereksinimi ile karşılaştıran çalışmalar bulunmaktadır. ${ }^{[18,19]}$ Bu çalışmaların ortak sonuçları, 75 yaş üstü yaş grubunda TKAÇ yönteminin 
daha başarılı olduğu yönündedir. Konu ile ilgili yapılan en geniş çalışma, 14 ülkenin ulusal veri tabanı kullanılarak yapılan ve yaklaşık 219 bin primer TKA cerrahisi geçiren hastayı kapsayan bir meta-analizdir. ${ }^{[3]}$ Çalışmanın sonucu; 75 yaş üstü hasta grubunda TKAÇ yönteminin aşikâr olarak daha başarılı olduğu; bununla birlikte, $45-64$ ve $65-74$ yaş grupları içerisinde de TKAÇ yöntemi daha başarılı görülse de, istatistiksel olarak yaşlı hasta grubu kadar kuvvetli verilerin olmadığı şeklinde bildirilmiştir.

\section{Yazarların Görüşü}

Yukarıda, alt başlıklar halinde birçok meta-analiz sonuçları bildirilmiş olmasına rağmen, bu sonuçların günlük klinik pratiğe yansıması ortopedik cerrahlar için kafa karıştırıcı bir durum olarak varlığını sürdürmektedir. Yazarlar; son 25 yıldır sadece alt ekstremite artroplasti cerrahisi gerçekleştirmekte olup TKAÇ ve TKAÇs yöntemlerinin günlük klinik pratik içerisinde birbirlerine olan üstünlükleri konusunda düşüncelerini aşağıda sıralamaktadırlar. Geçtiğimiz 20 yıl içerisinde endüstri tarafından yapılan AR-GE çalışmaları sayesinde TKAÇ ve TAKÇs yöntemlerinin mutlak endikasyonları ve mutlak kontrendikasyonları ortadan kalkmıştır. Bu konuda en güzel örnek: geçmişte Dorr Tip 3 (soba borusu tipi) femura sahip osteoporotik ileri yaş hastalar için uygun çimentosuz femoral stem mevcut olmadığından TKAÇ yöntemi mutlak gerekli idi. Fakat günümüzde modüler ve silindirik gibi birçok distal (diyafiz) tutulumlu çimentosuz femoral stem mevcut olduğu için öneri, cerrahın kendini konforlu hissetti$\breve{g i}$, ameliyat sırasında iyatrojenik komplikasyonlardan uzak kalabileceği ve alışmış olduğu tespit yöntemidir. Bununla birlikte, TKAÇ ve TKAÇs, kıtalar arası cerrahi ekol farkı göstermektedir. Kuzey Amerika kıtasında TKAÇ ekolü, Kuzey Avrupa ülkelerinde ise TKAÇs ekolü benimsenmiştir; bu durum, güncel literatürdeki çalışmaların kaynağı ile ülke veri tabanı bazlı çalışmaların sonucunu etkilemektedir.

TKAÇ ve TKAÇs yöntemlerine ait meta-analizlerde, erken dönem fonksiyonel sonuçlar TKAÇ yöntemi lehine sonuçlanmaktadır. Bu durumun nedenleri arasında, çimentosuz yöntemde femoral stemde oluşacak osteoentegrasyonun en iyi şekilde olması için mümkün olduğu kadar kortikal kemiği spongiyöz kemikten ayırmak için yapılan oyma nedeniyle oluşan ön uyluk ağrısı sayılabilir. Fakat, günümüzde double taper stemler kullanıma sunulmuş olup, ön uyluk ağrısı komplikasyonu klinik pratikte daha az oranda saptanmaktadır. Tüm bunlara ek olarak, TKAÇs yöntemi TKAÇ yöntemine göre daha kolay uygulanabilir bir yöntemdir ve ameliyat sonrası tromboemboli gibi ölümcül seyirli komplikasyonlar açısından daha güvenlidir.
Güncel literatür taramasında, bu konu ile ilgili çalışmalarda; "TKAÇ yöntemi" ile "ileri yaş hasta" terimleri bir arada çok sık görülmeye başlanmıştır. Fakat yazarlara göre, TKA cerrahisinde kullanılacak tespit yönteminin belirlenmesinde yaştan ziyade hastanın ne kadar aktif ya da sedanter olduğu ve hasta beklentisi daha büyük rol teşkil etmektedir. Yazarların bu klinik uygulamasında en büyük rol sahibi, gelişen endüstri sayesinde kullanıma sunulan çimentosuz femoral stem çeşitleridir. TKAÇs yönteminde, femoral kanalı tam olarak femoral stem ile doldurmaya meyil edildiği için, ameliyat sırasında iyatrojenik kırık riski osteoporotik hastalara uygulanan bu yöntemde daha yüksek idi. Buna ek olarak, geçmişte kullanılan femoral stem geometrisi ve teknoloji yetersizliği nedeniyle, ileri yaş hastalarda ameliyat sonrası femoral stem osteoentegrasyonu daha yavaş olarak gerçekleşmekte idi. Fakat günümüzde, distal (diyafizer) tutulumlu femoral stemler sayesinde bu risk azalmış olup, tespit yöntemi belirlenmesinde hasta yaşından ziyade hasta beklentisinin daha önemli olduğu düşünülmektedir.

Yazarlar sadece alt ekstremite artroplasti cerrahisi gerçekleştirmekte olmalarına rağmen, çimentolu asetabular kap tespiti nadiren uygulamaktadırlar. Bununla birlikte, bu tespit yönteminin endikasyonları; asetabular kemik stoğunun ileri derecede kaybı, ileri inaktif hastalar ve geçirilmiş septik artrit zemininde yapılan TKA cerrahileri, yazarlara göre çimentolu asetabular kap yöntemi için endikasyon doğurmaktadır.

Sonuç olarak; gelişen artroplasti endüstrisi sayesinde, TKAÇ ve TKAÇs için mutlak endikasyonlar ve kontrendikasyonlar ortadan kalkmış bulunmaktadır. Fakat, yazarların özellikle vurgulamak istedikleri; TKA cerrahisinin ameliyat sonrası başarısında belirleyici olan hususun, farklı tespit yöntemlerinin uygulanmasından ziyade, yöntemin en iyi ve en doğru şekilde uygulanmasıdır. TKAÇs yöntemi osteoporotik hastalarda uygulanacak ise; kare kesitli, spongiyöz kemiği sıkıştırarak ilerleyen stemler veya distal (diyafizer) tutulumlu femoral stemler tercih edilmelidir. TKAÇ yöntemi kullanılacak ise: özenilerek ve tam olarak gerçekleştirildiğine emin olunan femoral medulla temizliği yanında 4. nesil çimentolama yöntemleri; vakum yardımlı çimento karıştırıcı, proksimal ve distal tıkaç, distal santralizör; TKA cerrahisinin mutlak uygulanacak aşamalarından olmalıdır.

\section{SONUÇ}

TKAÇ ve TKAÇs tespit yöntemleri, birçok alt başlık içerisinde karşılıklı olarak birbirine üstün yanlar barındırmaktadır. Fakat, başarı farklarının günlük pratik uygulamaya yansıması kısıtlıdır. Bununla birlikte, 
tüm literatürün aynı kanaatte olduğu birkaç alt başlık bulunmaktadır ki bunların klinik pratikte kullanılabilirliği daha değerlidir. Bunlardan birine göre; yaşlı hasta grubunda (75 yaş üstü) TKAÇ yöntemi uygun tespit yöntemi olarak düşünülmektedir. Bir diğerine göre; TKAÇ yöntemi, cerrahi maliyetleri düşünüldügünde, TKAÇs yöntemine göre daha düşük maliyetlidir. Son olarak; TKAÇ yöntemi kullanılırken ameliyat sırasında ve erken ameliyat sonrası olarak tromboemboli riski açısından tetikte olunmalıdır. Tüm bu bilgiler ışığında yazarların görüşü; kontrendike bir durum olmadığı sürece, cerrahın alışmış olduğu ve kendini konforlu hissettiği yöntemi kullanması, bu sayede ameliyat süresini kısaltarak birçok olası ameliyat sonrası komplikasyon riskini düşürmesi ve ameliyat sırasında oluşabilecek iyatrojenik komplikasyon riskini azaltması doğrultusundadır.

\section{KAYNAKLAR}

1. Abdulkarim A, Ellanti P, Motterlini N, Fahey $\mathrm{T}$, O'Byrne JM. Cemented versus uncemented fixation in total hip replacement: a systematic review and meta-analysis of randomized controlled trials. Orthop Rev 2013;5(1):8. Crossref

2. Phedy P, Ismail HD, Hoo C, Djaja YP. Total hip replacement: A meta-analysis to evaluate survival of cemented, cementless and hybrid implants. World J Orthop 2017;8(2):192. Crossref

3. Huddleston HD. Femoral lysis after cemented hip arthroplasty. J Arthroplasty 1988;3(4):285-97. Crossref

4. Amstutz HC, Yao J, Dorey FJ, Nugent JP. Survival analysis of T-28 hip arthroplasty with clinical implications. Orthop Clin North Am 1988;19(3):491-503.

5. Hozack WJ, Rothman RH, Booth REJr, Balderston RA, Cohn JC, Pickens GT. Survivorship analysis of 1,041 Charnley total hip arthroplasties. J Arthroplasty 1990;5(1):41-7. Crossref

6. Kim YH, Suh JS. Low incidence of deep-vein thrombosis after cementless total hip replacement. J Bone Joint Surg Am 1988;70(6):878-82. Crossref

7. Unnanuntana A, Dimitroulias A, Bolognesi MP, Hwang $\mathrm{KL}$, Goodman SB, Marcus RE. Cementless femoral prostheses cost more to implant than cemented femoral prostheses. Clin Orthop Relat Res 2009;467:1546-51. Crossref
8. Grant P, Aamodt A, Falch J, Nordsletten L. Differences in stability and bone remodeling between a customized uncemented hydroxyapatite coated and a standard cemented femoral stem. A randomized study with use of radiostereometry and bone densitometry. J Orthop Res 2005;23(6):1280-5. Crossref

9. Karrholm J, Malchau H, Snorrason F, Herberts P. Micromotion of femoral stems in total hip arthroplasty. A randomized study of cemented, hydroxyapatite-coated, and porous-coated stems with roentgen stereo-photogrammetric analysis. J Bone Joint Surg Am 1994;76(11):1692-705. Crossref

10. McCombe $P$, Williams SA. A comparison of polyethylene wear rates between cemented and cementless cups. A prospective, randomised trial. J Bone Joint Surg Br 2004;86-B(3):344-9. Crossref

11. Onsten I, Carlsson AS. Cemented versus uncemented socket in hip arthroplasty. A radiostereometric study of 60 randomized hips followed for 2 years. Acta Orthop Scand 1994;65(5):517-21. Crossref

12. Reigstad A, Rokkum M, Bye K, Brandt M. Femoral remodeling after arthroplasty of the hip. Prospective randomized 5-year comparison of 120 cemented/uncemented cases of arthrosis. Acta Orthop Scand 1993;64(4):411-6. Crossref

13. Stea S, Comfort T, Sedrakyan A, Havelin L, Marinelli M, Barber T, Paxton E, Banerjee S, Isaacs AJ, Graves S. Multinational comprehensive evaluation of the fixation method used in hip replacement: interaction with age in context. J Bone Joint Surg Am 2014;96(Suppl 1):42-51. Crossref

14. Ström HK, Kolstad K, Mallmin H, Sahlstedt B, Milbrink J. Comparison of the uncemented Cone and the cemented Bimetric hip prosthesis in young patients with osteoarthritis: an RSA, clinical and radiographic study. Acta Orthop 2006;77(1):71-8. Crossref

15. Wykman A, Olsson E, Axdorph G, Goldie I. Total hip arthroplasty. A comparison between cemented and press-fit noncemented fixation. J Arthroplasty 1991;6(1):19-29. Crossref

16. Laupacis A, Bourne R, Rorabeck C, Feeny D, Tugwell P, Wong C. Comparison of total hip arthroplasty performed with and without cement: a randomized trial. J Bone Joint Surg Am 2002;84-A(10):1823-8. Crossref

17. Dear KBG. Iterative generalized least squares for metaanalysis of survival data at multiple times. Biometrics 1994;50(4):989-1002. Crossref

18. Kalaian $A$, Raudenbush $S$. A multivariate mixed linear model for meta-analysis. Psychol Methods 1996;1(3):227-35. Crossref

19. Kutner $\mathrm{MH}$, Nachtsheim CJ, Neter J, Li W. Applied Linear Statistical Models, 5th ed. New York: McGraw-Hill / Irwin; 2005. 